\title{
Shield Optimization in Simple Geometry for the Gateway Concept
}

\author{
R.K. Tripathi ${ }^{1}$, L.C. Simonsen ${ }^{1}$ J.E. Nealy ${ }^{2}$ P.A. Troutman ${ }^{1}$, and J.W. Wilson ${ }^{1}$ \\ ${ }^{1}$ NASA Langley Research Center, Hampton, VA \\ ${ }^{2}$ Old Dominion University, Norfolk, VA
}

\begin{abstract}
The great cost of added radiation shielding is a potential limiting factor in many deep space missions. For this enabling technology, we are developing tools for optimized shield design over multi-segmented missions involving multiple work and living areas in the transport and duty phase of various space missions. The total shield mass over all pieces of equipment and habitats is optimized subject to career dose and dose rate constraints. Preliminary studies of deep space missions indicate that for long duration space missions, improved shield materials will be required. The details of this new method and its impact on space missions and other technologies will be discussed. This study will provide a vital tool for evaluating Gateway designs in their usage context. Providing protection against the hazards of space radiation is one of the challenges to the Gateway infrastructure designs. We will use the mission optimization software to scope the impact of Gateway operations on human exposures and the effectiveness of alternate shielding materials on Gateway infrastructure designs. This study will provide a guide to the effectiveness of multifunctional materials in preparation to more detailed geometry studies in progress.
\end{abstract}

\section{INTRODUCTION}

Shield mass can be a high-cost factor in system designs for the long-term operations required in deep space operations, and optimization methods in the design process will be critical to cost-effective progress in space development [1]. Limiting the time of transfer to duty station or the mission time within the solar cycle as well as the choice of materials used in construction can reduce the shield mass required on specific missions [2]. Such a procedure is adequate for shield design for a space exploratory mission or a space tourist. Unfortunately, requirements for the crew operating a transportation infrastructure are quite different since an astronaut will enter service and have missions once or twice a year over a ten-year career. In this case, the shield design process is very different.

Much of the protection within a space structure is provided by the structural elements, onboard materials, and equipment required for other purposes and the means of making the best choice of materials among various options is critical to the protective qualities of the overall design. Multifunctional materials (for example, structural elements that have good shielding properties) will be common in the optimization process. Furthermore, the design decisions cannot be made in a vacuum and multidisciplinary design methods need to be developed. The need for multifunctional/multidisciplinary design techniques was identified as critical to the cost-effective development of space several years ago [1] and expanded on recently [2].

In the past, an amount of exposure was assigned to each mission segment and developed as a subjective strategy with relative improvements of costs through material trades dependent on off-optimum design solutions. In this study, the optimization method for minimum mass determination is used in performing trade studies to enable objective trade reduction costs since strategies for meeting exposure constraints are optimized over the entire mission architecture for each trade. In addition to optimized design trades, we will also consider the implementation of the principle of as low as reasonably achievable (ALARA) required by federal regulation and normally ignored in mission design studies. The ALARA principle will be met by added protection of the crew quarters where members will spend a significant fraction of each day sleeping. The main crew quarter design will also be used as the shelter from potential solar particle events during the mission. In this respect, we assume an adequate strategy for exposure limitation during EVA activity is available, and the design is mainly the habitable volume and crew quarter/SPE shelter. Emergency planning in the case of an accidental SPE exposure will have to be part of the overall mission plan and is not considered in the present study.

In the present study, we will consider two singular baseline missions, a 47 day Lunar mission, a baseline 62 day L1 mission to a deep space platform assuming $\mathrm{Al} 2219$ as the reference construction material. Two multiuse infrastructure operation missions are considered, 30-day lunar missions and 37-day L1 missions (e.g., telescope). Trades on materials for construction of the living/working space and crew quarter shielding and impact on costs through a change in launch mass will be used to quantify the savings. In addition to the material trade studies, propulsion engine trade studies can be performed by change in mission scenario time lines. 


\section{EXPOSURE AND OTHER CONSTRAINTS}

The present exposure constraints used in the space program are recommended for low Earth orbit (LEO) operations by the National Council on Radiation Protection [3] and approved by the NASA Administrator and OSHA. There are no limits for deep space operations due to the unusual composition of the GCR and the resultant uncertainties in associated health risks. The NCRP did recommend that the limits for low earth orbit (LEO) operations could be used as a guide in deep space operational studies [3]. New exposure recommendations are now approved by the NCRP [4] and the new LEO limits are given the three critical organs of skin, ocular lens, and blood forming organ (BFO) in tables 1 and 2 and will be used herein recognizing the associated uncertainties. We use dose equivalent for the Gy-Eq since insufficient data will not allow Gy-Eq evaluation at this time.

Table 1-Recommended organ dose equivalent limits for all ages.

\begin{tabular}{|c|c|c|c|}
\hline & BFO, Sv & Eye, Sv & Skin, Sv \\
\hline Career & See Table 2 & 4.0 & 6.0 \\
\hline Annual & 0.50 & 2.0 & 3.0 \\
\hline 30 Days & 0.25 & 1.0 & 1.5 \\
\hline
\end{tabular}

Table 2-Career whole body-dose equivalent limit (Sv) for lifetime excess risk of fatal cancer of three percent as a function of age at exposure.

\begin{tabular}{|l|l|l|l|l|}
\hline Age & 25 & 35 & 45 & 55 \\
\hline Male & 0.7 & 1.0 & 1.5 & 2.9 \\
\hline Female & 0.4 & 0.6 & 0.9 & 1.6 \\
\hline
\end{tabular}

In the present work, the optimized mission will be taken as the minimum mass to meet mission requirements and not exceed the exposure constraints in tables 1 and 2. The present design considerations are for the main habitable areas. The volume limited crew quarters where a large fraction of personal time is spent will have added protection to further reduce exposures (ALARA) and will also be designed to provide the shelter from a solar particle event.

Aside from the radiation health risks, the psychological well being and its impact on crew performance also affects the shield design [5]. Crew performance level is related in part to the length of the mission and the volume of the work/living areas of the spacecraft. The design performance levels of Optimal, Performance Limit, and Tolerable are shown in figure 1 as a function of duration of the stay. Rather small volumes are useful over short time periods but long missions require sufficient space for a crew to perform at reasonable levels. We will use the Optimal design for the habitable volume and the Tolerable design for the crew quarters which will also serve as the SPE shelter.

Table 3 -- Performance levels descriptions

\begin{tabular}{|c|l|}
\hline Performance index & Performance level description \\
\hline 1 & $\begin{array}{l}\text { Optimal performance limit } \\
\text { best suited for long duration } \\
\text { with minimal impact on crew } \\
\text { performance }\end{array}$ \\
\hline 2 & $\begin{array}{l}\text { Performance limit allows crew } \\
\text { demands to be met but not } \\
\text { well suited for long duration }\end{array}$ \\
\hline 3 & $\begin{array}{l}\text { Tolerable limit provides space } \\
\text { for astronaut to survive but not } \\
\text { well suited for other than } \\
\text { emergencies }\end{array}$ \\
\hline
\end{tabular}

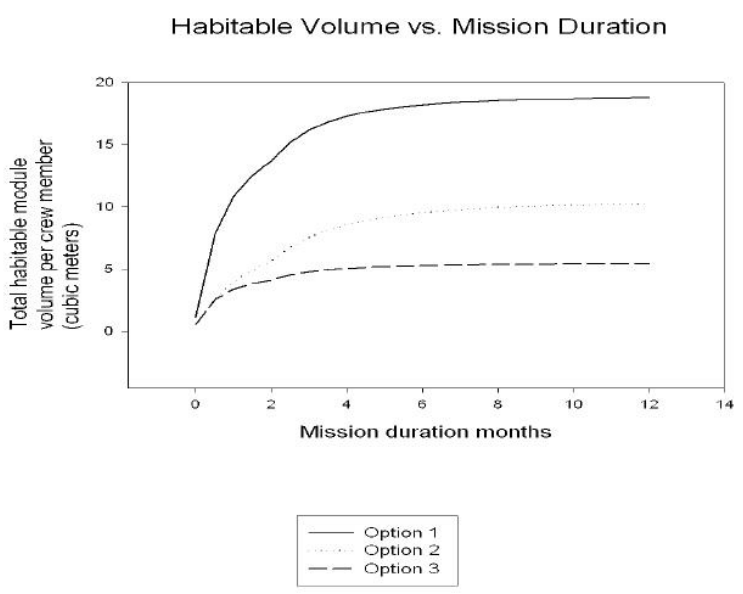

Fig. 1. Habitable volume for given mission duration.

\section{SPACE ENVIRONMENT AND SHIELDING MATERIALS}

In order to quantify radiation exposure in space, it is required that the external ambient ionizing radiation environment be specified in terms of individual constituents and their respective energy fluxes. A great quantity of observational space environmental data from instrumented space platforms has been amassed in recent decades and used in developing computer models serving to define, as well as possible, the composition and temporal behavior of the space environment [6]. From the standpoint of radiation protection for 
humans in interplanetary space, the heavy ions (atomic nuclei with all electrons removed) of the galactic cosmic rays (GCR) and the sporadic production of energetic protons from large solar particle events (SPE) must be dealt with. The GCR environmental model used herein is based on a current version in which ion spectra are modulated between solar maxima and minima according to terrestrial neutron monitor data assuming the radial dependent diffusion model of Badhwar et al. [7], as described in reference [8] by Wilson et al. The modeled spectra for solar minimum in 1977 and Solar Maximum in 1990 as given by Badhwar are shown in figure 2. The required historic and projected Sunspot numbers along with the corresponding Deep River Neutron Monitor count rates are shown in figure 3. There is only a few percent difference between the environment measured near Earth and what is observed at other locations near the Earth's orbit about the sun. These anticipated differences are less than the model uncertainty and will be ignored in the present study.

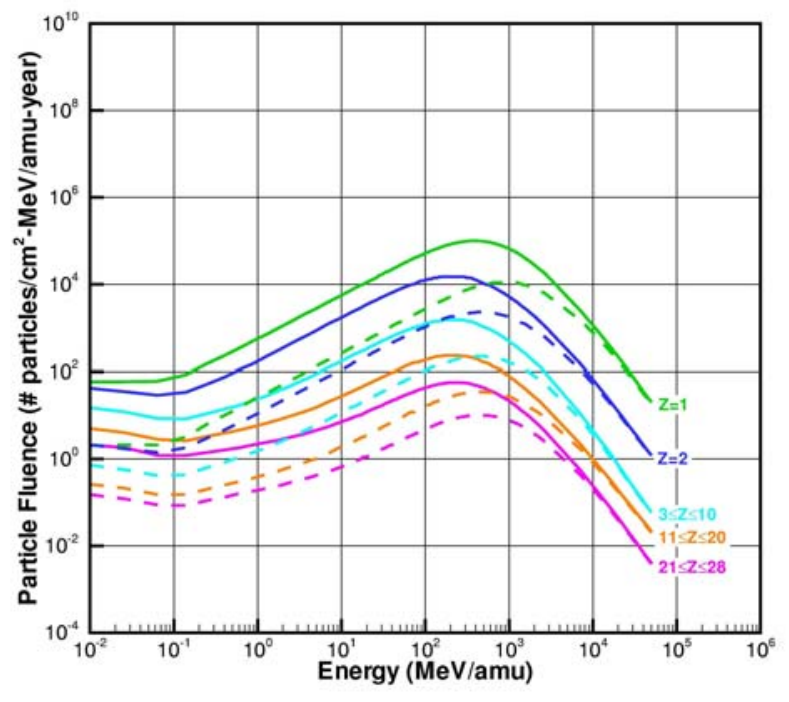

Fig. 2. Galactic cosmic ray spectra at the 1977 Solar Minimum (full lines) and 1990 Solar Maximum (dashed lines) according to Badhwar et al.

The environment near a large celestial body is modified by interaction with local materials producing an induced environment and shielding within the subtended angle of such a large body. The surface exposure on a lunar plain is shielded below the horizon but experiences an induced environment (mainly but not exclusively neutrons) produced in the local surface. The lunar surface GCR environment is shown in figure 4 at the 1977 Solar Minimum and the 1990 Solar Maximum. In addition to the GCR ions streaming from overhead, large numbers of neutrons are produced in the lunar surface materials and diffuse from below the surface as shown in the figure.

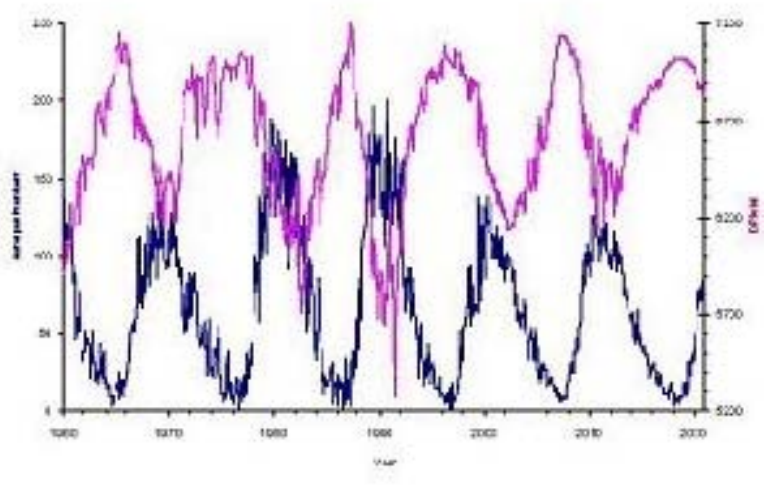

Fig. 3. Sunspot number (blue) and Deep River Neutron Monitor (pink) count rate for 1960 to 2022.

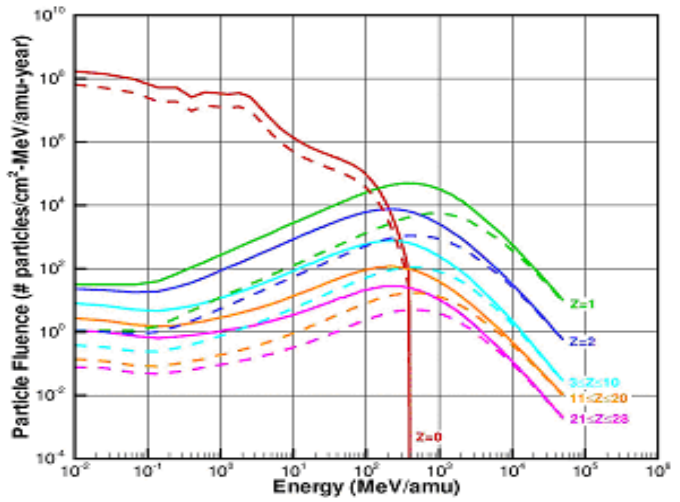

Fig. 4. GCR environment during the 1977 Solar Minimum (full lines) and the 1990 Solar Maximum (dashed lines) on the lunar surface.

Large SPE have only been observed to occur during times of increased solar activity conditions, and very large energetic events of grave important to human protection occur only infrequently (avg. 1 or 2 per cycle) and only outside of two years of solar minimum. 
Among the large events, the largest observed ground level event of the last 60 years of observation is that of February 23,1956 which produced a 3600 percent increase in neutron monitor levels on the terrestrial surface. The next largest event observed is the September 29, 1989 event with ground level increases of 400 percent or an order of magnitude smaller than that of the Feb. 1956 event. Numerous other ground level events of smaller magnitude have occurred but are a factor of four and more lower in magnitude than the Sept. 1989 event. It is known that large SPEs are potentially mission threatening, and astronauts in deep space must have access to adequate shelter from such an occurrence. The SPE particle energy spectrum used here has been derived from the event, which took place on September 29, 1989. To provide a baseline worst-case scenario we assume an event of the order of four times larger than the September 29, 1989 event as an event comparable to the August 4, 1972 event from the point of view of space exposure. The September $1989 \mathrm{SPE}$ spectrum is shown in figure 5. If we meet 30-day dose rate constraints on an event four times larger than the September 1989 event then it is unlikely that an added factor of two or so larger events (like that of Feb. 23, 1956) would have serious medical consequences. The rationale and plausibility for this model is described by Kim et al. [9].

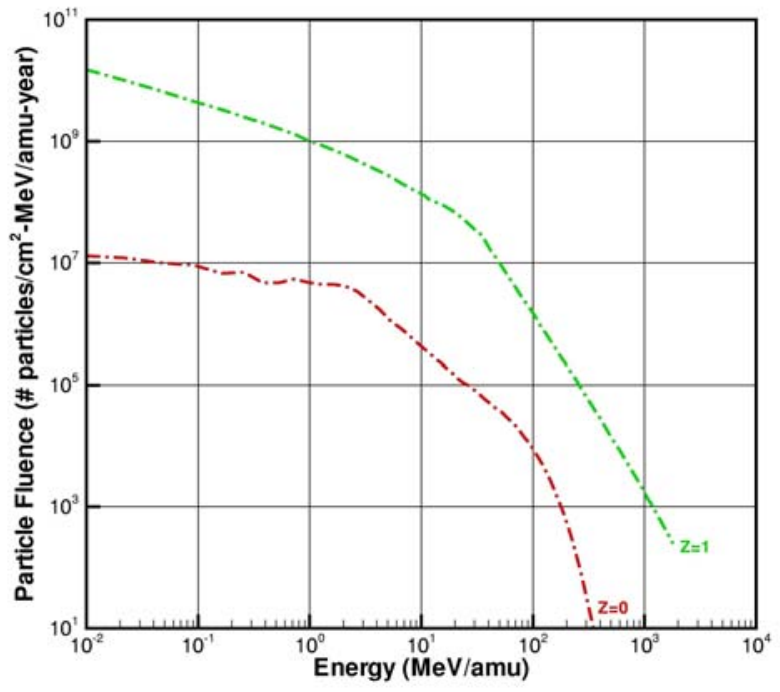

Fig. 5. SPE spectrum during September 1989 as observed near Earth.

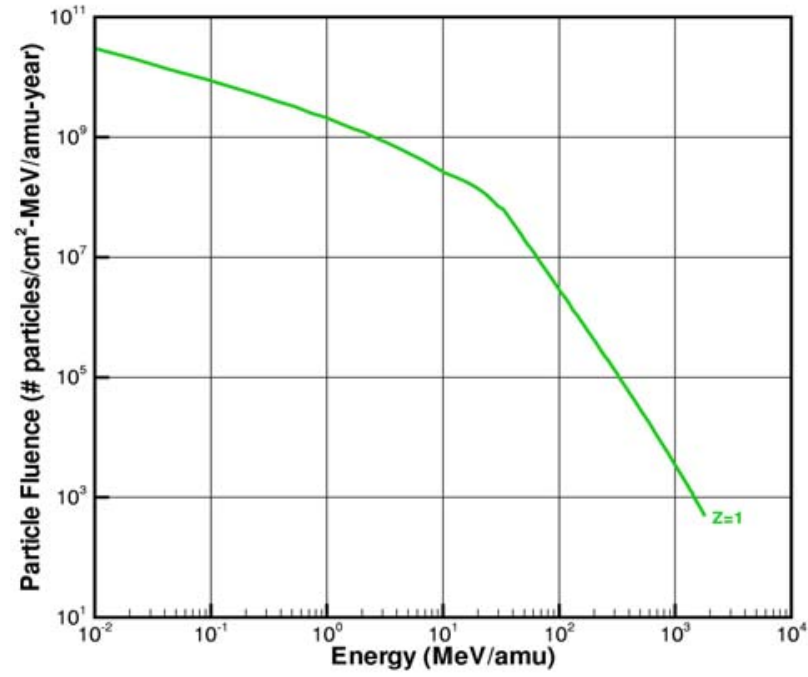

Fig. 6. The lunar surface environment during the September 1989 SPE.

The SPE are likewise altered by the presence of a large body similar to the GCR. The corresponding lunar surface environment is shown in figures 6 . The role of the neutrons on the lunar surface is less effective in causing exposure relative to the protons streaming from overhead. Note that is in contrast to the more energetic GCR wherein large numbers of neutrons are produced in the lunar surface materials (see figure 4).

The effectiveness of a given shield material is characterized by the transport of energetic particles within the shield, which is in turn defined by the interactions of the local environmental particles (and in most cases, their secondaries) with the constituent atoms and nuclei of the shield material. These interactions vary greatly with different material types. Materials in the present study are given in table 4. For space radiation shields, materials with high hydrogen content generally have greater shielding effectiveness, but often do not possess qualities that lend themselves to the required structural integrity of the space vehicle or habitat. Organic polymers are the exception. The design of properly-shielded spacecraft and habitats for long-duration human presence in interplanetary space will thus require an approach tending toward optimization of a compromise between protective shielding and various other functional aspects of the onboard materials. Candidate multifunctional materials for such an optimization approach have been chosen here to represent various contributing elements in a vehicle shield design. Liquid hydrogen and methane are possible fuels that in large quantities may contribute substantially to overall protection. Aluminum has long been a spacecraft material of choice although various forms of polymeric materials show enhanced protection properties such as polyethylene. The polysulfone and polyetherimide are high performance structural polymers. Lithium hydride is a popular shield material for nuclear power reactors, but is generally not useful for other functions. The graphite nanofiber materials heavily impregnated with hydrogen may well represent a viable multifunctional component in future space structures, and its inclusion here should presently be considered as not yet state-of-the-art.

The results of detailed transport calculations for these materials have been incorporated into a shield design database. Important in this respect is their chemical composition and mass density given in table 4. The shield effectiveness for the above-discussed environments were evaluated using the HZETRN code with improved nron transport procedures [10]. The exposures to critical organ tissues were evaluated for each environment within spherical shells of each material. The time dependent dose rates are evaluated within the shielding materials assuming exposure in the center of a large volume with varying wall thickness. 
Table 4. Chemical composition of materials used in the present study

\begin{tabular}{|c|c|c|c|c|c|c|}
\hline Material & ID & Atom & $\mathbf{Z}$ & $\mathbf{A}$ & atoms/g & $\begin{array}{c}\text { Density } \\
\text { g/cm }\end{array}$ \\
\hline \multirow{6}{*}{$\begin{array}{c}\text { Aluminum } \\
2219\end{array}$} & ALM & $\mathrm{Al}$ & 13 & 27 & $2.08 \mathrm{E}+22$ & 2.83 \\
\hline & & $\mathrm{Ti}$ & 22 & 48 & $7.53 \mathrm{E}+18$ & \\
\hline & & $\mathrm{V}$ & 23 & 51 & $1.18 \mathrm{E}+19$ & \\
\hline & & $\mathrm{Mn}$ & 25 & 55 & $3.31 \mathrm{E}+19$ & \\
\hline & & $\mathrm{Cu}$ & 29 & 64 & $5.90 \mathrm{E}+20$ & \\
\hline & & $\mathrm{Zr}$ & 40 & 91 & $1.19 \mathrm{E}+19$ & \\
\hline \multirow{4}{*}{$\begin{array}{c}\text { Poly- } \\
\text { etherimide }\end{array}$} & PEI & $\mathrm{H}$ & 1 & 1 & $2.44 \mathrm{E}+22$ & 1.27 \\
\hline & & $\mathrm{C}$ & 6 & 12 & $3.76 \mathrm{E}+22$ & \\
\hline & & $\mathrm{N}$ & 7 & 14 & $2.03 \mathrm{E}+21$ & \\
\hline & & $\mathrm{O}$ & 8 & 16 & $6.10 \mathrm{E}+21$ & \\
\hline \multirow[t]{4}{*}{ Polysulfone } & PSF & $\mathrm{H}$ & 1 & 1 & $3.00 \mathrm{E}+22$ & 1.24 \\
\hline & & $\mathrm{C}$ & 6 & 12 & $3.68 \mathrm{E}+22$ & \\
\hline & & $\mathrm{O}$ & 8 & 16 & $5.45 \mathrm{E}+21$ & \\
\hline & & $\mathrm{S}$ & 16 & 32 & $1.36 \mathrm{E}+21$ & \\
\hline \multirow[t]{2}{*}{ Poly-ethylene } & PET & $\overline{\mathrm{H}}$ & 1 & 1 & $8.60 \mathrm{E}+22$ & 0.92 \\
\hline & & $\mathrm{C}$ & 6 & 12 & $4.30 \mathrm{E}+22$ & \\
\hline \multirow{2}{*}{$\begin{array}{l}\text { Lithium } \\
\text { Hydride }\end{array}$} & LIH & $\mathrm{H}$ & 1 & 1 & $7.53 \mathrm{E}+22$ & 0.82 \\
\hline & & $\mathrm{Li}$ & 3 & 7 & $7.53 E+22$ & \\
\hline \multirow{2}{*}{$\begin{array}{c}\text { Liquid } \\
\text { Methane }\end{array}$} & LME & $\mathrm{H}$ & 1 & 1 & $1.51 \mathrm{E}+23$ & 0.466 \\
\hline & & $\mathrm{C}$ & 6 & 12 & $3.76 \mathrm{E}+22$ & \\
\hline \multirow{2}{*}{$\begin{array}{c}\text { Graphite } \\
\text { Nanofibers }\end{array}$} & GNF & $\mathrm{H}$ & 1 & 1 & $4.07 \mathrm{E}+23$ & 2.25 \\
\hline & & $\mathrm{C}$ & 6 & 12 & $1.63 \mathrm{E}+22$ & \\
\hline $\begin{array}{c}\text { Liquid } \\
\text { Hydrogen }\end{array}$ & LH2 & $\mathrm{H}$ & 1 & 1 & $6.03 \mathrm{E}+23$ & 0.07 \\
\hline
\end{tabular}

The annual dose rates within the Al 2219 alloy shield are shown for ocular lens and BFO in figures 7 and 8. Large variations in exposure of critical organs are seen to occur over time and with increasing shielding. 
Lens (Al 2219)

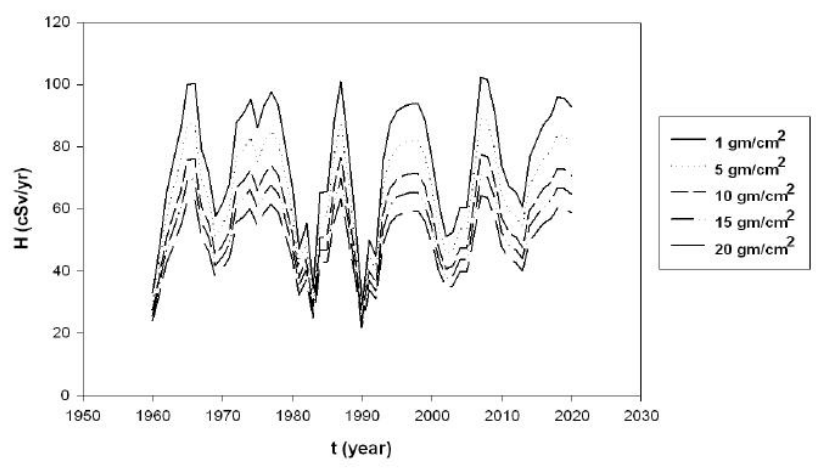

Fig. 7. Annual dose equivalent to ocular lens within an Al 2219 shielded region.

BFO (Al2219)

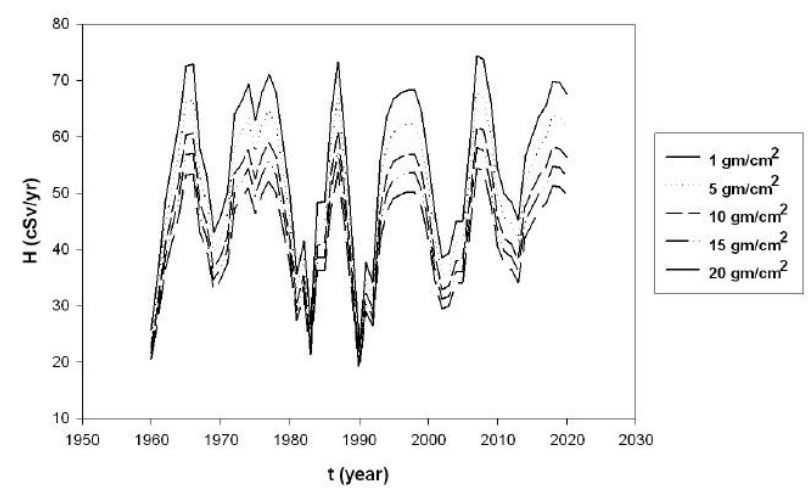

Fig. 8. Annual dose equivalent to BFO within an Al 2219 shielded region.

\section{CONSTRAINTS AND OPTIMIZATION}

The general principles required to optimize a mission is implemented in this section. In the absence of a specific design, we start with assumptions to be used in estimating exposures and shield mass. A baseline vehicle design will include Al 2219 alloy construction and evaluate shield mass assuming $40 \%$ of the solid angle is shielded by vehicle components constructed of Al alloy (assumed to be $30 \mathrm{~g} / \mathrm{cm}^{2}$ over $15 \%$ of the solid angle and $60 \mathrm{~g} / \mathrm{cm}^{2}$ for the remaining $25 \%$ ) and normally different than the shield material comprising the remaining $60 \%$ of the total solid angle. Only the shield mass requirements for the remaining $60 \%$ of the solid angle are taken herein as shielding. Lacking a specific vehicle design, we assume an isotropic distribution of radiation within the habitable volume thus simplifying the analysis. A framework for mission architectural optimization will be established here which will allow later specific designs to be introduced and optimized.

The habitable volume will be assumed to cover the entire solid angle with a constant thickness. The required crew living space will be for optimal performance and calculated assuming a right circular cylinder with 2.2 meter height. The three critical organs (skin, lens, BFO) identified by the NCRP will be used in designing the shield as follows. Let $R_{j}(x)$ be the dose equivalent rate to the $j^{\text {th }}$ critical organ within a shield of thickness $\mathrm{x}$ calculated from the time dependent environments. In addition to the GCR background, we will assume that if we are not within two years of solar minimum that a design limit solar event occurs (4 times Sept. 1989 event) and that an additional shelter is available which is a tolerable volume for such a short duration (see figure 1). We assume the shelter volume is a right circular cylinder of 2 meter height with Tolerable living requirements. Dose rate and career dose limitations are required for the shield design process over the appropriate time intervals. For example, a mission to the L1 in three segments (Earth to $\mathrm{L} 1$ trip in time $\mathrm{T}_{1}$, time on duty of $\mathrm{T}_{2}$, and return trip of duration $\mathrm{T}_{3}$ ) would first have to meet a requirement similar to

$$
\mathrm{R}_{\mathrm{j}}\left(\mathrm{x}_{1}\right) \mathrm{T}_{1}+\mathrm{R}_{\mathrm{j}}\left(\mathrm{x}_{2}\right) \mathrm{T}_{2}+\mathrm{R}_{\mathrm{j}}\left(\mathrm{x}_{3}\right) \mathrm{T}_{3}+\mathrm{H}_{\mathrm{spe}}\left(\mathrm{x}_{\mathrm{spe}}\right)<\mathrm{L}_{\mathrm{j}}
$$


where $x_{i}$ is the shield thickness of the ith segment of the mission and $L_{j}$ is the exposure limitation. The thirty-day and annual dose rate constraints must be applied over each mission segment where the SPE drives the crew quarter shield design. We assume $\mathrm{x}_{1}=\mathrm{x}_{3}$ for missions in which the transport vehicle is common to both transport segments with corresponding assumptions on required mass. The $L_{j}$ is the accepted exposure limit to the $j^{\text {th }}$ critical organ defined for LEO operations. Note, $x_{i}, i=1-3$ are greater than $1 \mathrm{~g} / \mathrm{cm}^{2}$ in order to meet micrometeoroid impact requirements. Note, the above prescription does not account for the ALARA principle. Herein, the shelter is assigned to be the sleep quarters as one form of ALARA.

There are many combinations of $\mathrm{x}_{1}, \mathrm{x}_{2}, \mathrm{x}_{3}$, and $\mathrm{x}_{\mathrm{spe}}$ which satisfy the constraints above so that one must optimize the shielding by minimizing the total shield mass subject to the above constraints as follows:

$$
\operatorname{Min}\left\{\mathrm{V}_{\mathrm{s}}\left(\mathrm{x}_{1}\right)+\mathrm{V}_{\mathrm{s}}\left(\mathrm{x}_{2}\right)+\mathrm{V}_{\mathrm{s}}\left(\mathrm{x}_{3}\right)+\mathrm{V}_{\mathrm{s}}\left(\mathrm{x}_{\mathrm{spe}}\right)\right\} \cdot \rho=\mathrm{M}_{\mathrm{m}}
$$

where $\mathrm{V}_{\mathrm{s}}$ is the shield volume of each mission segment associated with the required living volume of optimum performance or the crew quarter/shelter as appropriate. Note, $\mathrm{V}_{\mathrm{s}}\left(\mathrm{x}_{3}\right)$ is set to zero if the same transport vehicle is used in segments 1 and 3.

We now set up the logic for implementing the computational procedures outlined above. We will think beyond the optimization of a given vehicle or habitat and approach the problem of optimizing a given defined mission architecture. The first step in the process of finding an optimum mission architecture is specification of the mission start time, the sequence of mission segments with the associated required equipment, the crew member characteristics associated with each segment, the desired crew performance level on each segment, the construction materials for the shield on each segment, and the associated locations where the segment occurs. These aspects of the mission are described by elements of the mission architectural profile matrix as shown in table 5. Note that within this profile we only allow sequential mission segments and no multisegmented capability is allowed at this stage of development. Note, the last two row entries in table 5 will be taken as initial estimates of the design variables (shield thickness) to be optimized.

Table 5. Mission Architectural Profile Matrix

\begin{tabular}{|c|c|c|c|c|}
\hline \multicolumn{5}{|c|}{ Mission title and start date: $\mathrm{T}_{0}$} \\
\hline Segment no. & 1 & 2 & 3 & $\ldots$ \\
\hline Duration, days & $\mathrm{T}_{1}$ & $\mathrm{~T}_{2}$ & $\mathrm{~T}_{3}$ & $\ldots$ \\
\hline Min. helio-radius & $\mathrm{R}_{\min 1}$ & $\mathrm{R}_{\min 2}$ & $\mathrm{R}_{\min 3}$ & $\ldots$ \\
\hline Max. helio-radius & $\mathrm{R}_{\max 1}$ & $\mathrm{R}_{\max 2}$ & $\mathrm{R}_{\max 3}$ & $\ldots$ \\
\hline Crew no. & $\mathrm{N}_{1}$ & $\mathrm{~N}_{2}$ & $\mathrm{~N}_{3}$ & $\ldots$ \\
\hline Females & $\mathrm{F}_{1}$ & $\mathrm{~F}_{2}$ & $\mathrm{~F}_{3}$ & $\ldots$ \\
\hline Min. age & $\mathrm{FA}_{1}$ & $\mathrm{FA}_{2}$ & $\mathrm{FA}_{3}$ & $\ldots$ \\
\hline Males & $\mathrm{M}_{1}$ & $\mathrm{M}_{2}$ & $\mathrm{M}_{3}$ & $\ldots$ \\
\hline Min. age & $\mathrm{MA}_{1}$ & $\mathrm{MA}_{2}$ & $\mathrm{MA}_{3}$ & $\ldots$ \\
\hline Performance & $\mathrm{Perf}_{1}$ & $\mathrm{Perf}_{2}$ & $\mathrm{Perf}_{3}$ & $\ldots$ \\
\hline Equipment & $\mathrm{Eq}_{1}$ & $\mathrm{Eq}_{2}$ & $\mathrm{Eq}_{3}$ & $\ldots$ \\
\hline Location & $\mathrm{Loc}_{1}$ & $\mathrm{Loc}_{2}$ & $\mathrm{Loc}_{3}$ & $\ldots$ \\
\hline Shield material & $\mathrm{Mat}_{1}$ & $\mathrm{Mat}_{2}$ & $\mathrm{Mat}_{3}$ & $\ldots$ \\
\hline Shield thickness & $\mathrm{x} 1$ & $\mathrm{x} 2$ & $\mathrm{x} 3$ & $\ldots$ \\
\hline Shelter thickness & $\delta 1$ & $\delta 2$ & $\delta 3$ & $\ldots$ \\
\hline
\end{tabular}

The mission duration is of course an important factor affecting the shield design. In addition, the crew size, composition, and expected performance levels all affect the shield design of the specific equipment required for a given segment. The total crew number and performance level (see figure 1 and table 3) will determine the volume of space required for a given segment and the associated wall area which must be shielded. The presence of females and their minimum age will often drive the dose rate constraints since the allowable career exposure of females is substantially less than males of the same age (see table 2). Age also determines the allowable career exposures for both males and females. Requiring the female crew to be approximately ten years older than their male counter parts effectively results in career limitations that no longer depend on gender.

In the present procedures, we will allow only a limited amount of hardware in the optimization process but will attempt to allow sufficient generality to expand to a more complex array of equipment, habitats, and vehicles. We will allow transfer vehicles for various transport segments of a mission allowing up to nine such unique vehicles denoted by indices of 1 through 9 . If two segments use the same vehicle it will have the same index for each segment and a mapping of design thickness into a unique optimization parameter set must be made in the analysis. Similarly, each habitat will have a unique identifier denoted by index 11 to 19 . This will constitute the only allowable hardware in the present study. Clearly this can be generalized by defining spacesuits as 21 to 29 and rovers as 31 to 39 and so on as required (see table 6) 
Table 6. Mission equipment designation numbers.

\begin{tabular}{|c|c|}
\hline Mission equip. & Designated indices, Eqi \\
\hline Transfer vehicles & $1-9$ \\
Habitats & $11-19$ \\
Spacesuits & $21-29$ \\
Rovers & $31-39$ \\
$\ldots$ & $\ldots$ \\
\hline
\end{tabular}

There are three locations where mission segments of interest may occur which are near earth for which we identify location indices as given in table 7. The lunar environment is modified by interaction with surface materials. These environments are applied as appropriately to the mission segments.

Table 7. Mission location indices

\begin{tabular}{|c|c|}
\hline Location & Location index, Loci \\
\hline Deep space & 1 \\
Lunar surface & 2 \\
Martian surface & 3 \\
\hline
\end{tabular}

The standard material associated with human activity has mainly been aluminum alloy 2219 although 6061 has also played a role. For construction of the walls of the habitable volume, other materials will generally provide greater protection. Many of these materials may be structural elements or materials on board for other purposes. The Graphite nanofiber/H is a hydrogenated herringbone graphite structure capable of absorbing more than its weight of hydrogen. The current list of materials in the database and the associated material indices used in the present study are given in table 8. The last two entries into the mission profile are the shield wall thickness $\mathrm{x}_{\mathrm{i}}$ and shelter/crew quarter thickness $\delta \mathrm{i}$ as initially estimated for each segment.

Table 8. Shield materials and material indices

\begin{tabular}{|c|c|}
\hline Shield material & Materials index, Mati \\
\hline Al 2219 & 1 \\
Polyetherimide & 2 \\
Polysulfone & 3 \\
Polyethylene & 4 \\
Lithium hydride & 5 \\
Liquid methane & 6 \\
Graphite nanofiber/H & 7 \\
Liquid hydrogen & 8 \\
\hline
\end{tabular}

The first analysis task is to calculate the mission background dose rate to each critical organ over all the mission segments and configurations. This allows the assumption of a SPE at the worst time in each segment as will be treated subsequently. The background dose rates throughout the mission are established using the database on annual dose within the materials, the location, the specific equipment involved, and the specified shield thickness. The mission dose rate (per day) over the period $t_{\text {start }}$ to $t_{\text {start }}+t_{1}+t_{2}+$ $\mathrm{t}_{3}+\ldots$ is given as

$$
\begin{aligned}
& \left\{\mathrm{Hj}_{1}\left(\mathrm{x}_{1}, \mathrm{Eq}_{1}, \mathrm{Mat}_{1}, \mathrm{t}\right) / 365 \mathrm{t}_{\text {start }} \leq \mathrm{t}<\mathrm{t}_{\text {start }}+\mathrm{t}_{1}\right. \\
\mathrm{R}_{\mathrm{j}}(\mathrm{t})= & \left\{\mathrm{H}_{\mathrm{j} 2}\left(\mathrm{x}_{2}, \mathrm{Eq}_{2}, \mathrm{Mat}_{2}, \mathrm{t}\right) / 365 \quad \mathrm{t}_{\text {start }}+\mathrm{t}_{1} \leq \mathrm{t}<\mathrm{t}_{\text {start }}+\mathrm{t}_{1}+\mathrm{t}_{2}\right. \\
& \left\{\mathrm{Hj} 3\left(\mathrm{x}_{3}, \mathrm{Eq}_{3}, \mathrm{Mat}_{3}, \mathrm{t}\right) / 365 \mathrm{t}_{\text {start }}+\mathrm{t}_{1}+\mathrm{t}_{2} \leq \mathrm{t}<\mathrm{t}_{\text {start }}+. .\right.
\end{aligned}
$$

where appropriate equipment geometry and location is implied for each segment. Note, $R_{j}(t)$ is to be evaluated for each critical organ type $\mathrm{j}$. The dose rate is used to establish exposure constraints and evaluation of the impact of a SPE on the mission design.

The dose rate for each segment depends on the time, the location, the equipment, and the shield material. Since the space radiation is isotropic one obtains some simplification in evaluating dose rate. The dose rate for the $\mathrm{j}^{\text {th }}$ critical organ and $\mathrm{i}^{\text {th }}$ segment within a transfer vehicle (e.g., $\mathrm{Eq}_{\mathrm{i}}=1$ to 9 ) is given as

$$
\mathrm{R}_{\mathrm{ji}}\left(\mathrm{x}_{\mathrm{i}}, \mathrm{Mat}_{\mathrm{i}}, \mathrm{t}\right)=\left[0.6 \mathrm{H}_{\mathrm{i}}\left(\mathrm{x}_{\mathrm{i}}, \mathrm{Mat}_{\mathrm{i}}, \mathrm{l}=1, \mathrm{t}\right)+0.15 \mathrm{H}_{\mathrm{j}}(30, \mathrm{Al}, \mathrm{l}=1, \mathrm{t})+0.25 \mathrm{H}_{\mathrm{j}}(60, \mathrm{Al}, \mathrm{l}=1, \mathrm{t})\right] / 365
$$

where $1=1$ denotes the location in Deep Space as is appropriate for the transfer and the contributions from $\mathrm{Al}$ accounts for the basic vehicle structure assumed to be constructed of $\mathrm{Al} 2219$. The dose rate for a segment on the lunar or Mars surface will assume (for now) only exposures while in the habitat (e.g., $\mathrm{Eq}_{\mathrm{i}}=11$ to 19 ) as

$$
\mathrm{R}_{\mathrm{ji}}\left(\mathrm{x}_{\mathrm{i}}, \mathrm{Mat}_{\mathrm{i}}, \mathrm{t}\right)=\mathrm{H}_{\mathrm{i}}\left(\mathrm{x}_{\mathrm{i}}, \mathrm{Mat}_{\mathrm{i}}, \mathrm{l}=2 \text { or } 3, \mathrm{t}\right) / 365
$$


where $1=2$ or 3 denotes a location on the lunar or Martian surface. Of course, a habitat in space (say L1) would have $1=1$. Effectively, we assume only a small fraction of time is in an exploration EVA mode and adequate means of avoiding a SPE is available. These issues will be addressed in greater detail in a subsequent analysis. The associated shield mass depends on the number of crew $\mathrm{N}_{\mathrm{i}}$ and the desired performance level Perf $\mathrm{i}_{\mathrm{i}}$ as follows.

The habitable volume for a given performance level Perf $\mathrm{f}_{\mathrm{i}}$ and duration $\mathrm{t}_{\mathrm{i}}$ for either the transfer vehicle or habitat with $\mathrm{N}_{\mathrm{i}}$ crew members is given by

$$
\mathrm{V}_{\mathrm{i}}=\mathrm{V}_{\text {Perfi }}\left(\mathrm{t}_{\mathrm{j}}\right) \mathrm{N}_{\mathrm{i}}
$$

where the specific volume $\mathrm{V}_{\text {Perfi }}\left(\mathrm{t}_{\mathrm{i}}\right)$ is given in figure 1 with Perf $f_{\mathrm{i}}$ the desired performance level and $\mathrm{t}_{\mathrm{i}}$ the segment duration. Assuming a right circular cylinder of 2.2 meter height, the associated cylindrical radius is

$$
\mathrm{r}_{\mathrm{i}}=\sqrt{ }\left[\mathrm{V}_{\mathrm{i}} /(2.2 \pi)\right]
$$

and the associated shield mass of the segment is

$$
\mathrm{M}_{\mathrm{i}}\left(\mathrm{x}_{\mathrm{i}}\right)=\rho \pi\left(\mathrm{r}_{\mathrm{i}}+\frac{\mathrm{x}_{\mathrm{i}}}{100 \rho}\right)^{2}\left(2.2+\frac{\mathrm{x}_{\mathrm{i}}}{100 \rho}\right)-2.2 \rho \pi \mathrm{r}_{\mathrm{i}}{ }^{2}
$$

where $x_{i}$ is the areal density of the shield material in $\mathrm{g} / \mathrm{cm}^{2}$ and $\rho$ is the matter density $\left(\mathrm{g} / \mathrm{cm}^{3}\right)$. The mass calculated by equation $(8)$ is in metric ton. Multiply $\mathrm{M}_{\mathrm{i}}$ 's by 1000 to get the mass in kilogram units. In the present study, we will assume that all equipment satisfies the same relations to performance level, crew size, and time.

The design must accommodate a possible SPE during any time except within two years of solar minimum. Furthermore, the exposure for any 30-day or annual period must satisfy dose rate constraints to prevent occurrence of deterministic effects. In this respect, we will allow for a very rare SPE which is $4 \mathrm{x}$ the September 29, 1989 event for design purposes and the assumption of an even larger event is on the order of few percent per year (only one such event seen in last 60 years). A storm shelter will be assumed to be the crew quarters where the crew spends a significant fraction of the day sleeping and in leisure activity and is placed within the habitable volume that is the primary shielded region. As such the shelter wall will be taken as $\mathrm{x}_{\mathrm{spe}}=\mathrm{x}_{\mathrm{i}}+\delta_{\mathrm{i}}$ where $\delta_{\mathrm{i}}$ represents the crew quarter wall shield thickness and assumed (for now) to be of the same material as the shield material for that segment. Similarly, for SPE shelter is evaluated with Perf $=3$ (Tolerable performance) for a duration of one day we have

$$
\mathrm{V}_{\mathrm{i}, \text { spe }}=\mathrm{V}_{3}(1 \mathrm{~d}) \mathrm{N}_{\mathrm{i}}
$$

Assuming the shelter to be a 2 meter high right circular cylinder results in an associated cylindrical radius of

and the associated shelter shield mass is

$$
r_{i, \text { spe }}=\sqrt{ }\left[V_{i, \text { spe }} /(2 \pi)\right]
$$

$$
\mathrm{M}_{\mathrm{i}, \text { spe }}\left(\mathrm{x}_{\mathrm{i}}\right)=\rho \pi\left(\mathrm{r}_{\mathrm{i}, \text { spe }}+\frac{\delta_{\mathrm{i}}}{100 \rho}\right)^{2}\left(2+\frac{\delta_{\mathrm{i}}}{100 \rho}\right)-2 \rho \pi \mathrm{r}^{2}{ }_{\mathrm{i}, \text { spe }}
$$

We then run an accumulation assuming the SPE occurs in segment $i$ as follows.

First we find the time of occurrence of the maximum of $\mathrm{H}_{\mathrm{i}}\left(\mathrm{x}_{\mathrm{i}}, \mathrm{t}_{\mathrm{imax}}\right)$ as follows

$$
\int_{\mathrm{t}}^{\mathrm{t}+\Delta} \mathrm{R}_{\mathrm{j}}\left(\mathrm{t}^{\prime}\right) \mathrm{dt} \mathrm{t}^{\prime}+\mathrm{H}_{\mathrm{j}, \text { spe }}\left(\mathrm{x}_{\mathrm{SPE}}\right)[1-\mathrm{U}(\mathrm{t}, \Delta)]=\mathrm{H}_{\mathrm{j}}(\mathrm{t}, \Delta)
$$

where $\mathrm{U}(\mathrm{t}, \Delta)$ is unity if both $\mathrm{t}$ or $\mathrm{t}+\Delta$ are within two years of solar minimum and contains $\mathrm{t}_{\mathrm{imax}}$. We maximize $\mathrm{H}_{\mathrm{j}}(\mathrm{t}, \Delta)$ for $\Delta=1$ month and 12 months on each segment $i$ and each organ type $j$. We require

$$
\mathrm{H}_{\mathrm{j}}\left(\mathrm{t}_{\max }, \Delta\right)<\mathrm{L}_{\mathrm{j}}(\Delta)
$$

In addition to the dose rate constraints, the career limits constraint will be applied assuming no prior exposures as

$$
\int \mathrm{R}_{\mathrm{j}}\left(\mathrm{t}^{\prime}\right) \mathrm{dt} \mathrm{t}^{\prime}+\mathrm{H}_{\mathrm{jspe}}\left(\mathrm{x}_{\mathrm{spe}}\right)<\mathrm{L}_{\mathrm{j}}\left(\text { age }_{\mathrm{min}}, \text { gender }\right)
$$

assuming $\mathrm{H}_{\mathrm{spp}}\left(\mathrm{x}_{\mathrm{spe}}\right)$ as the maximum over all segments.

The mass of the shield that is to be minimized depends on the volume being protected and the areal density required to meet dose constraints. The specific volume (volume per crewmember) depends on duration and performance level as shown in figure 1 . The total shield mass relation depends on the mission. For example, the Mars Reference Mission assumes that the transit to Mars and return to Earth are different vehicles so that the total mass is

$$
\mathrm{M}_{\mathrm{n}}\left(\mathrm{x}_{1}, \mathrm{x}_{2}, \mathrm{x}_{3}, \delta_{1}, \delta_{2}, \delta_{3,}\right)=\mathrm{M}_{1}+\mathrm{M}_{2}+\mathrm{M}_{3}+\mathrm{M}_{1, \mathrm{spe}}+\mathrm{M}_{2, \mathrm{spe}}+\mathrm{M}_{3, \mathrm{spe}}
$$

Whereas, the L1 mission (and lunar/asteroid missions) use ( $\mathrm{M}^{\prime}=\max \left\{\mathrm{M}_{1}, \mathrm{M}_{3}\right\}$ and $\left.\mathrm{x}_{1}=\mathrm{x}_{3}\right)$ so the total mass is 


$$
\mathrm{M}_{\mathrm{n}}\left(\mathrm{x}_{1}, \mathrm{x}_{2}, \delta_{1}, \delta_{2}\right)=\mathrm{M}^{\prime}+\mathrm{M}_{2}+\mathrm{M}_{1, \text { spe }}+\mathrm{M}_{2, \text { spe }}
$$

The corresponding mass is minimized over the unique equipment $\mathrm{x}_{\mathrm{i}} \mathrm{s}$ and $\delta_{\mathrm{i}} \mathrm{s}$ subject to constraints (13) and (14). In general, the mission mass is the sum over unique equipment used over all the segments

$$
\mathrm{M}=\Sigma \mathrm{M}_{\mathrm{i}}
$$

The computational procedure must account for all of these specific mission aspects. We now define the baseline reference missions for which the trades will be evaluated.

\section{SINGULAR MISSION ARCHITECTURE}

In this section, we will examine the singular missions including trades on shield materials. The missions to be considered are the near Earth 100-day class missions such as a lunar or a L1 mission. The craft reference construction material will always be taken as Aluminum 2219 alloy. This is the dominant material used in the Shuttle and International Space Station and represents current standard practice. The initial mission profile matrix will be given along with the optimized results for aluminum shielding to be used as a baseline for further study. Material trades are then made using the materials in table 4 in comparison to aluminum.

L1 SINGULAR MISSION -There are several possible missions to L1 for not only space science but as a possible gateway to deep space exploration to asteroids or Mars. A reference profile for a singular L1 mission is for 18 days in transit from and back to LEO with a 26-day mission stay. The crew size is taken as four members with careers in midlife (40 years of age). The optimized profile for aluminum 2219 alloy is shown in table 9. The mass of the aluminum shield is about 4.5 metric tons. The main protection requirement is against the solar particle events that may occur, and the driver is the 30-day dose rate limit in table 1 . In this mission we assume a single vehicle used as a habitat at the site.

Trades have been studied for the L1 baseline mission material given in table 9 for the materials listed in table 4 . The optimized mass for using various materials is shown in figure 9. As an example, an optimized profile for graphite nanofibers is shown in table 10, and the associated shield mass is found to be 2 metric tons and is achieved using the graphite nanofiber/H experimental energy storage material. As on can see from the tables, the areal density of graphite nanofiber/H material is a factor of 2.5 less than that required for Al2219 alloy.

Table 9. L1 Singular Mission Architectural Profile Matrix for Al2219 Shielding

\begin{tabular}{|l|c|c|c|}
\hline $\mathrm{L} 1 / \mathrm{T}_{0}=1 / 1 / 2014$ & 1 & 2 & 3 \\
\hline Segment no. & 18 & 26 & 18 \\
\hline Duration, days & 1.0 & 1.0 & 1.0 \\
\hline Min. helio-radius, AU & 1.0 & 1.0 & 1.0 \\
\hline Max. helio-radius, AU & 4 & 4 & 4 \\
\hline Crew no. & 2 & 2 & 2 \\
\hline Females & 40 & 40 & 40 \\
\hline Min. age & 2 & 2 & 2 \\
\hline Males & 40 & 40 & 40 \\
\hline Min. age & 1 & 1 & 1 \\
\hline Performance & 1 & 1 & 1 \\
\hline Equipment & 1 & 1 & 1 \\
\hline Location & 1 & 1 & 1 \\
\hline Shield material & 1 & 1 & 1 \\
\hline Shield thickness, $\mathrm{g} / \mathrm{cm}^{2}$ & 34.76 & 34.76 & 34.76 \\
\hline Shelter thickness, g/cm & & & \\
\hline
\end{tabular}

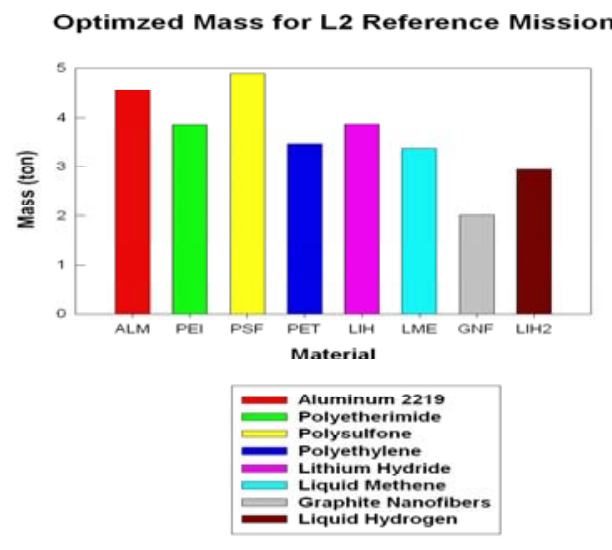

Fig. 9. Optimized mass for L1 reference and trade missions for various materials.

LUNAR SINGULAR MISSION-The lunar singular mission profile will be taken as a 4.5-day transit to an L1 with a 2-day layover followed by a 2-day trip to the lunar surface. The surface stay is for 30 days followed by a 2-day return to L1 with a second 2-day layover followed by a 4.5-day return to LEO. The trip begins on March 3, 2018 near solar minimum. The crew size is taken as four middle aged men and women of equal numbers. The optimized reference profile is given in table 11. Note there are several pieces of equipment involved in this scenario which affects the overall mass. This mission falls within two years of solar minimum, and no SPE is expected to occur. Only minimum shielding is required, and material type plays no role. 
Table 10. L1 Singular Mission Architectural Profile Matrix for Nanofiber/H Shielding

\begin{tabular}{|l|c|c|c|}
\hline $\mathrm{L} 1 / \mathrm{T}_{0}=1 / 1 / 2014$ & 1 & 2 & 3 \\
\hline Segment no. & 18 & 26 & 18 \\
\hline Duration, days & 1.0 & 1.0 & 1.0 \\
\hline Min. helio-radius, AU & 1.0 & 1.0 & 1.0 \\
\hline Max. helio-radius, AU & 4 & 4 & 4 \\
\hline Crew no. & 2 & 2 & 2 \\
\hline Females & 40 & 40 & 40 \\
\hline Min. age & 2 & 2 & 2 \\
\hline Males & 40 & 40 & 40 \\
\hline Min. age & 1 & 1 & 1 \\
\hline Performance & 1 & 1 & 1 \\
\hline Equipment & 1 & 1 & 1 \\
\hline Location & 7 & 7 & 7 \\
\hline Shield material & 1 & 1 & 1 \\
\hline Shield thickness, $\mathrm{g} / \mathrm{cm}^{2}$ & 14. & 14. & 14. \\
\hline Shelter thickness, $\mathrm{g} / \mathrm{cm}^{2}$ & &
\end{tabular}

Table 11. Initial Lunar Singular Mission Architectural Profile Matrix for Al2219 Shielding

\begin{tabular}{|l|c|c|c|c|c|c|c|}
\hline \multicolumn{2}{|l|}{ Lunar/ $\mathrm{T}_{0}=3 / 6 / 2018$} \\
\hline Segment no. & 1 & 2 & 3 & 4 & 5 & 6 & 7 \\
\hline Duration, days & 4.5 & 2 & 2 & 30 & 2 & 2 & 4.5 \\
\hline $\begin{array}{l}\text { Min. helio- } \\
\text { radius, AU }\end{array}$ & 1. & 1. & 1. & 1. & 1. & 1. & 1. \\
\hline $\begin{array}{l}\text { Max. helio- } \\
\text { radius, AU }\end{array}$ & 1. & 1. & 1. & 1. & 1. & 1. & 1. \\
\hline Crew no. & 4 & 4 & 4 & 4 & 4 & 4 & 4 \\
\hline \multicolumn{1}{|c|}{ Females } & 2 & 2 & 2 & 2 & 2 & 2 & 2 \\
\hline \multicolumn{1}{|c|}{ Min. age } & 40 & 40 & 40 & 40 & 40 & 40 & 40 \\
\hline \multicolumn{1}{|c|}{ Males } & 2 & 2 & 2 & 2 & 2 & 2 & 2 \\
\hline \multicolumn{1}{|c|}{ Min. age } & 40 & 40 & 40 & 40 & 40 & 40 & 40 \\
\hline Performance & 1 & 1 & 1 & 1 & 1 & 1 & 1 \\
\hline Equipment & 1 & 11 & 2 & 12 & 2 & 11 & 1 \\
\hline Location & 1 & 1 & 1 & 2 & 1 & 1 & 1 \\
\hline $\begin{array}{l}\text { Shield material } \\
\text { index }\end{array}$ & 1 & 1 & 1 & 1 & 1 & 1 & 1 \\
\hline $\begin{array}{l}\text { Shield thickness, } \\
\text { g/cm }\end{array}$ & 1 & 1 & 1 & 1 & 1 & 1 & 1 \\
\hline $\begin{array}{l}\text { Shelter thickness, } \\
\text { g/cm }\end{array}$ & 1 & 1 & 1 & 1 & 1 & 1 & 1 \\
\hline
\end{tabular}

The lunar singular mission material trade has been studied for the reference mission profile given in table 11, and the optimized mass is shown in figure 10. This mission falls within two years of Solar minimum and no SPE is expected to occur. Minimum shielding is required and material type plays no essential role. As a result, table 10 is also the profile for trades for all the materials. The small differences in shield mass is due to the differences in geometry resulting from different densities of the shielding materials. 


\section{Optimzed Mass for Lunar Reference Mission}

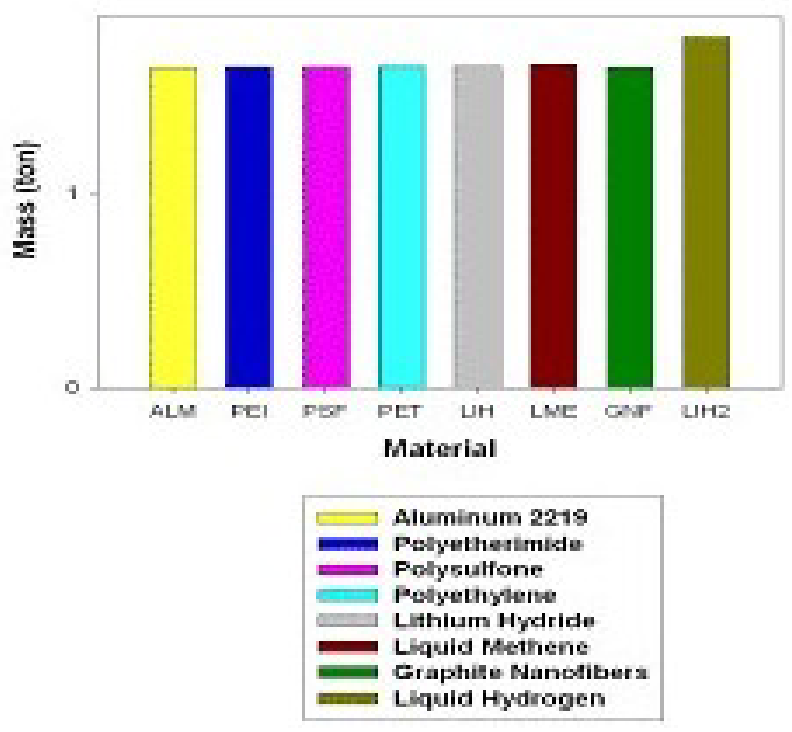

Fig. 10. Optimized mass for Lunar reference and trade missions for various materials.

\section{GATEWAY INFRASTRUCTURE}

The Gateway infrastructure [11] is described elsewhere and provides a transportation network for near Earth missions but also a staging area for deep space exploration. The transportation infrastructure is assumed to be operated by career astronauts as a service to exploration and development of space including commercialization. Inherent in the assumptions made by the NCRP in arriving at the LEO career dose limits in tables 1 and 2 , is that the astronaut will have a ten year career starting at a specified age $[3,4]$. We assume herein that the astronaut will perform two trips a year throughout a ten year career or a total of 20 trips. The career exposure constraint is then written as

$$
20 \int \mathrm{R}_{\mathrm{j}}\left(\mathrm{t}^{\prime}\right) \mathrm{dt} \mathrm{t}^{\prime}+2 \mathrm{H}_{\mathrm{jspe}}\left(\mathrm{x}_{\mathrm{spe}}\right)<\mathrm{L}_{\mathrm{j}}\left(\text { age }_{\text {min }}, \text { gender }\right)
$$

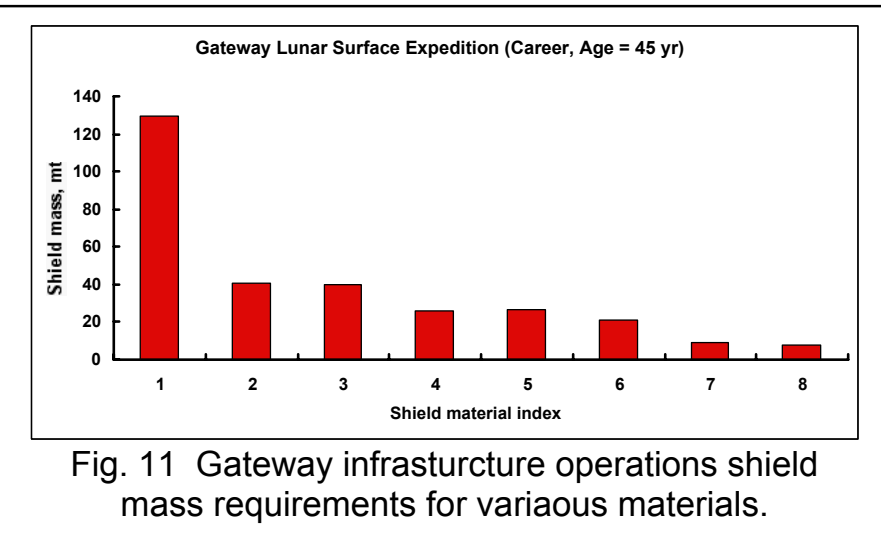

where 20 combines the exposure over 20 trips and the factor 2 occurs since only 1 or 2 large solar particle events will occur in a given solar cycle (about 10.5 year duration). The dose rate in equation (18) is taken as the average value over the solar cycle. Unlike the singular missions where shield design is dominated by the possibility of solar particle events, the operation of the infrastructure will be dominated by the galactic cosmic ray exposures for which the limits in table 1 and 2 have large uncertainties. In this case, the shield requirements are tentative and may be quite different when the design uncertainty is reduced. We will consider two classes of missions separately as if crews are assigned to specific mission classes. 
LUNAR TRANSPORTATION INFRASTRUCTURE-The lunar mission profile will be taken as a 6-day transit to an L1 with a 5-day layover followed by a 2.5-day trip to the lunar surface with four separate pieces of equipment to support different mission segments. The surface stay is for 3-days followed by a 2.5-day return to L1 with a second 5-day layover and 6-day return to LEO. The crews consist of four men and women beginning their careers at age 45 and beginning in 2010 and continuing to 2020. The initial profile matrix is given in table 12 .

Table 12. Gateway Lunar Surface Expedition Initial Profile

\begin{tabular}{|l|c|c|c|c|c|c|c|}
\hline \multicolumn{1}{|c|}{ Date of Mission: 2010-2020 } & 1 & 2 & 3 & 4 & 5 & 6 & 7 \\
\hline Segment no. & 6 & 5 & 2.5 & 3 & 2.5 & 5 & 6 \\
\hline Duration, days & $\mathrm{hr}$ & $\mathrm{hr}$. & $\mathrm{hr}$. & $\mathrm{hr}$. & $\mathrm{hr}$. & $\mathrm{hr}$. & $\mathrm{hr}$. \\
\hline Min. helio-radius, AU & $\mathrm{Hr}$ & $\mathrm{Hr}$ & $\mathrm{Hr}$ & $\mathrm{Hr}$ & $\mathrm{Hr}$ & $\mathrm{Hr}$ & $\mathrm{Hr}$ \\
\hline Max. helio-radius, AU &. &. &. &. &. &. &. \\
\hline Crew no. & 4 & 4 & 4 & 4 & 4 & 4 & 4 \\
\hline \multicolumn{1}{|c|}{ Females } & 2 & 2 & 2 & 2 & 2 & 2 & 2 \\
\hline Min. age & 45 & 45 & 45 & 45 & 45 & 45 & 45 \\
\hline Males & 2 & 2 & 2 & 2 & 2 & 2 & 2 \\
\hline Min. age & 35 & 35 & 35 & 35 & 35 & 35 & 35 \\
\hline Performance & 1 & 1 & 1 & 1 & 1 & 1 & 1 \\
\hline Equipment & 1 & 11 & 2 & 12 & 2 & 11 & 1 \\
\hline Location & 1 & 1 & 1 & 2 & 1 & 1 & 1 \\
\hline Shield material index & 1 & 1 & 1 & 1 & 1 & 1 & 1 \\
\hline Shield thickness, g/cm & 1 & 1 & 1 & 1 & 1 & 1 & 1 \\
\hline $\begin{array}{l}\text { Shelter thickness, } \\
\text { g/cm }\end{array}$ & 1 & 1 & 1 & 1 & 1 & 1 & 1 \\
\hline
\end{tabular}

$\mathrm{hr}$ (minimum heliocentric radii) $=0.9974 \mathrm{AU}$

$\mathrm{Hr}($ maximum heliocentric radii $)=1.0026 \mathrm{AU}$

The dose rate exposure constraints remain the same but the career limits are given by equation (18). The resulting shield mass for this 45-year-old crew is shown in figure 11. It is clear in this case that the present aluminum alloy base technology will be inadequate and development of advanced materials concepts will be enabling technology for the operation of such infrastructure. This will even be more true when reliability based design methods are implemented.

Table13. Gateway Telescope Construction Mission

\begin{tabular}{|l|c|c|c|}
\hline Segment no. & 1 & 2 & 3 \\
\hline Duration, days & 6 & 25 & 6 \\
\hline Min. helio-radius, AU & $\mathrm{hr}$ & $\mathrm{hr}$. & $\mathrm{hr}$. \\
\hline Max. helio-radius, AU & $\mathrm{Hr}$. & $\mathrm{Hr}$. & $\mathrm{Hr}$. \\
\hline Crew no. & 4 & 4 & 4 \\
\hline Females & 2 & 2 & 2 \\
\hline Min. age & 35 & 35 & 35 \\
\hline Males & 2 & 2 & 2 \\
\hline$\quad$ Min. age & 35 & 35 & 35 \\
\hline Performance & 1 & 1 & 1 \\
\hline Equipment & 1 & 11 & 1 \\
\hline Location & 1 & 1 & 1 \\
\hline Shield material index & 1 & 1 & 1 \\
\hline Shield thickness, $\mathrm{g} / \mathrm{cm}^{2}$ & 44.15 & 5.35 & 44.15 \\
\hline Shelter thickness, g/cm & 55.79 & 24.81 & 55.79 \\
\hline
\end{tabular}

$\mathrm{hr}($ minimum heliocentric radii $)=0.9974 \mathrm{AU}$

$\mathrm{Hr}($ maximum heliocentric radii $)=1.0026 \mathrm{AU}$ 


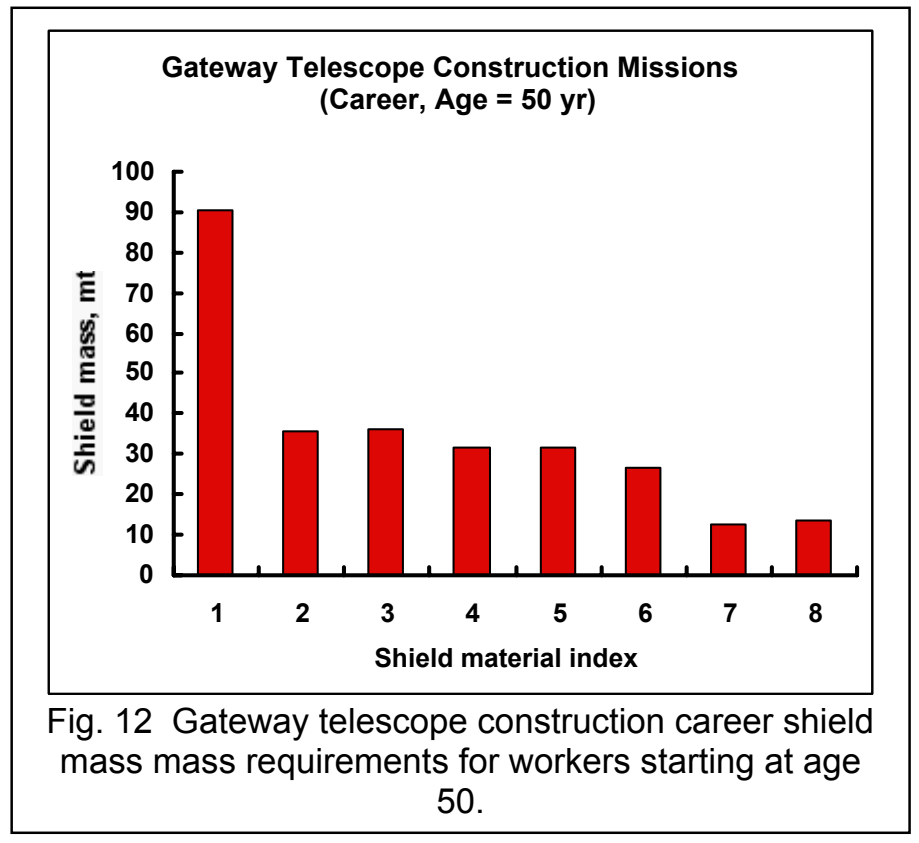

L1 TRANSPORTATION INFRASTRUCTURE -There are several possible missions to L1 for not only space science and tourism but as a possible gateway to deep space exploration to Mars and beyond. A reference profile for a single L1 mission is for 6 days in transit from and back to LEO with a 25 -day mission stay as given in table 13 for aluminum alloy based technology. The crew size is taken as four members with careers beginning at age 35. The optimized profile for a single lifetime mission in 2014 using aluminum 2219 alloy is shown in table 13. The total shield mass in this case is 27.3 metric tons. There is a strong age dependence, and increasing the age to 40 years eliminates the need for shielding in the wall beyond the minimum $1 \mathrm{~g} / \mathrm{cm}^{2}$ and the shelter shield to only $28.7 \mathrm{~g} / \mathrm{cm}^{2}$ resulting in only 7.4 metric tons of shield requirements for a single lifetime mission.

As can be seen, there is a great difference in requirements on age in addition to great differences in operation of the infrastructure over the astronaut career as was seen in the lunar scenario. If the astronaut crew spends their careers operating beginning at age 50 years, the L1 infrastructure shield requirements are shown in figure 12. It is clear from the shield masses in figure 12 that aluminum alloys stand out as poor candidate materials, and the development of new materials will have an important impact on the operation of the Gateway infrastructure.

\section{CONCLUSION}

Even the present limited study of developing 100-day mission capabilities outside the Earth's protective magnetic field brings a host of issues revealed but is not fully resolved in arriving at affordable solutions to further explore and develop space. A primary limitation of the current study is that reliability based methods to deal with the great uncertainties remain undeveloped. We do show that the once in a lifetime mission as was committed by NASA in the late 1960's and early 1970's are still possible under our current state of knowledge. The extension to operating a complex infrastructure with career astronauts immediately encounters massive shielding characteristic of a Mars mission scenario. The reason is simple, 20 few month missions add up to a long time for space exposure over the astronaut career. The next step is to develop reliability based design methods based on mainly the biological uncertainty of astronaut risks, which will greatly alter the current result.

\section{REFERENCES}

1. Wilson, J.W. et al. Chapter 1: Preliminary considerations. Shielding Strategies for Human Space Exploration. NASA CP 3360, 1997.

2. Wilson, J.W. et al, Issues in deep space radiation protection. Astronautica Acta. In press.

3. National Council on Radiation Protection \& Measurements, Guidance on Radiation Received in Space. NCRP Report 98, 1989.

4. National Council on Radiation Protection \& Measurements, Radiation Protection Guidance for Activities in Low Earth Orbit. NCRP Report 132, 2001.

5. Woolford, B. et al. Chapter 12: Human factors implications for shielding. Shielding Strategies for Human Space Exploration. NASA CP 3360, 1997. 
6. Badhwar, G.D. and O'Neill, P.M., Improved model of galactic cosmic radiation for space exploration mission, Nucl. Tracks \& Radiat., 20, 403-410, 1992

7. Badhwar G.D., et. al, Intercomparison of radiation measurements on STS-63;, Radiat. Meas. 26; 147-158; 1997

8. Wilson, J.W., Kim M-H, Shinn, J.L., Tai, H., Cucinotta, F.A., Badhwar, G.D., Badavi, F.F., Atwell, W.: Solar Cycle Variation and Application to the Space Radiation Environment, NASA/TP-1999-209369

9. Kim, M-H., Wilson, J.W., Simonsen, L.C., Cucinotta, F.A., Atwell, W., Badavi, F.F., Miller, J.: Contribution of High Charge and Energy (HZE) lons During Solar-Particle Event of September 29, 1989, NASA/TP-19999-209320.

10. Clowdsley, M. S. et al., Can. J. Phys. 78: 45-56; 2000.

11. Troutman, P. A, Private communication.

\section{CONTACT}

Ram K. Tripathi, Office: 757-864-1467, Fax: 757-864-8094 r.k.tripathi@larc.nasa.gov 